\title{
Clinical Profile of Hoarseness of Voice: A Hospital-Based Cross-Sectional Study
}

\author{
Nitin Deosthale ${ }^{1}$ Asha Jadia Soni ${ }^{2}$ Sonali Prabhakar Khadakkar ${ }^{1}$ Mateen Khursheed Wani \\ Kanchan Sandeep Dhote ${ }^{1}$ Disha Amar Methwani ${ }^{1}$ Pavani Garikapati ${ }^{1}$ Vivek Harkare ${ }^{1}$ \\ Priti Rakesh Dhoke ${ }^{1}$
}

${ }^{1}$ Department of ENT, N.K.P. Salve Institute of Medical Sciences and RC and LMH, Nagpur, Maharashtra, India

${ }^{2}$ Department of ENT, Hindu Hruday Samrat Balasaheb Thakeray

Trauma Care Centre, Mumbai, Maharashtra, India

Address for correspondence Sonali P. Khadakkar, MBBS, DORL, 39 Shivaji Housing Society, Near Chawadeshwari Mandir, New Subhedar Nagar, Nagpur, Maharashtra 440024, India (e-mail: sonalikhadakkar@yahoo.com).

Int J Recent Surg Med Sci 2022;8:44-48.

\begin{abstract}
Introduction Hoarseness is a symptom with a varied etiology ranging from inflammatory condition, benign lesions to malignant lesions. Benign conditions are more common than malignant. Proper knowledge of clinical profile and evaluation is necessary to treat the cause.

Objective It was conducted with the aim to study the clinical profile of patients with hoarseness of voice.

Materials and Methods It was a descriptive cross-sectional study of 2 years conducted at Department of ENT at Tertiary Health Care Hospital, India. Patients aged above 10 years presenting with hoarseness of voice were included in the study. After detailed history related to sociodemographic particulars, clinical examinations including Hopkin's rod examination in all patients and direct laryngoscopy, and radiological and histopathological examination were performed whenever indicated.

Results Out of total 100 patients, maximum patients (32\%) were in the age group of 21 to 30 years. There was slight male preponderance with male:female ratio of 1.17:1. Laborer (29\%) was the major group affected in terms of occupation. Most common predisposing factor was smoking (35\%). Commonest etiology for hoarseness of voice was chronic laryngitis (20\%).

Keywords

- hoarseness of voice

- laryngoscopy

- etiology

- vocal cord

Conclusion Hoarseness of voice as a symptom should never be ignored as its etiology may range from simple infection to malignancy. At our tertiary care center majority of patients come from rural area. Most of the etiological factors found in our study were treatable medically or surgically. Early diagnosis is the key to improve the outcome of treatment.
\end{abstract}

\section{Introduction}

Voice is an integral part of human attribute known as speech. It is a strong tool revealing a person's physical state.
A person with complaint regarding voice may present with hoarseness, voice fatigue, breathy voice, reduced phonation range, pitch breaks, etc. Hoarseness of voice is characterized by altered pitch, loudness, vocal effort, and quality that
DOI https://doi.org/

$10.1055 / \mathrm{s}-0041-1734400$

ISSN 2455-7420
C 2021. Medical and Surgical Update Society.

This is an open access article published by Thieme under the terms of the Creative Commons Attribution-NonDerivative-NonCommercial-License, permitting copying and reproduction so long as the original work is given appropriate credit. Contents may not be used for commercial purposes, or adapted, remixed, transformed or built upon. (https://creativecommons.org/licenses/by-nc-nd/4.0/).

Thieme Medical and Scientific Publishers Pvt. Ltd. A-12, 2nd Floor, Sector 2, Noida-201301 UP, India 
decrease voice-related quality of life or impair communication. It is just a symptom and not a disease.

Hoarseness can be of acute or chronic onset. Acute onset of hoarseness can be usually due to viral infections, voice abuse, trauma to the larynx, thyroid surgery, etc. While chronic onset is caused by benign or malignant lesions, chronic granulomatous diseases like tuberculosis or systemic diseases like diabetes mellitus. Benign conditions are more common than malignant conditions. ${ }^{2}$ It is a most common presenting symptom for more serious conditions that needs immediate intervention. If the hoarseness of the voice persists for more than 2 weeks, then it should be investigated properly to find the cause. ${ }^{3}$

\section{Objective}

The aim of the study was to study the clinical profile of patients with hoarseness of voice.

\section{Materials and Methods}

It was a descriptive cross-sectional study conducted at Department of ENT of Tertiary Health Care Hospital of Central India, from November 2017 to October 2019. All patients of either sex with hoarseness of voice of age above 10 years were included in the study, while patients with change in voice due to nasal and nasopharyngeal pathology, oral or oropharyngeal pathology, congenital laryngeal causes, voice disorders due to articulation disorders, central nervous system lesion like bulbar palsy, Wegner's granulomatosis, multiple sclerosis, stroke, and Parkinson's disease, and those refusing to give informed consent were excluded from the study.

Sample size was calculated in reference to Vengala et $\mathrm{a}^{4}$ study as follows:

$$
n=Z^{2} P(1-P) / d^{2}
$$

Where $n=$ sample size, $Z=1.96^{2}$ (Z statistic for a level of confidence), $p=30 \%$ (expected prevalence or proportion), $d=10 \%$ (absolute error)

$$
\begin{aligned}
n= & 1.96^{2} \times 0.3(1-0.3) /(0.10)^{2} \\
= & 80.64(\text { sample size })
\end{aligned}
$$

We included 100 cases in present study.

Detailed history related to sociodemographic particulars like age, gender, residence, occupation, habits, and previous medical and surgical history was noted. Personal and family history was enquired. Complete general and local examination of ear, nose, throat, head, and neck were done of each patient. Indirect laryngoscopy and Hopkin's rod examination of larynx and hypopharynx were done. Wherever required direct laryngoscopy with biopsy under general anesthesia was done. Computed tomography scan neck was done wherever required to evaluate the extent of tumor and tissue invasion. Management was done according to the diagnosis. The benign lesions were excised by microlaryngeal surgery and malignant lesions underwent treatment according to the site and staging of the tumor.

Statistical analysis was performed by entering the data into Microsoft Excel spreadsheet. Analysis was done using SPSS version 20 (IBM SPSS Statistics Inc., Chicago, Illinois, United States) Windows software program. Descriptive statistics included computation of percentages, means, and standard deviations. Chi-squared test and Fisher's exact test were used for qualitative data whenever two or more than two groups were used to compare.

\section{Results}

Total 100 patients were included in the study. As shown in - Table 1, the mean age of males who presented with hoarseness of voice was $41.05 \pm 17.94$ years and among the females, it was $37.58 \pm 13.59$ years. The age group ranged from 11 to 77 years. Majority of the patients (32\%) belonged to the age group of 21 to 30 years followed by 31 to 40 years (23\%). Out of 100 patients, $54 \%$ were males and $46 \%$ were females with a slight male predominance showing male to female ratio of $1.17: 1$. About $53 \%$ subjects were from rural area and $47 \%$ from urban area.

Laborer was the single largest group (29\%) followed by housewives (15\%) and farmers (13\%) who presented with hoarseness of voice. Occupations requiring excessive voice use if combined in a single group were $31 \%$ showing hoarse-

\begin{tabular}{|c|c|c|c|c|c|c|}
\hline \multirow{3}{*}{$\begin{array}{l}\text { Age groups in } \\
\text { years }\end{array}$} & \multicolumn{4}{|l|}{ Gender } & \multirow{2}{*}{\multicolumn{2}{|c|}{ Total }} \\
\hline & \multicolumn{2}{|l|}{ Male } & \multicolumn{2}{|l|}{ Female } & & \\
\hline & Frequency $(n)$ & Percentage (\%) & Frequency (n) & Percentage (\%) & Frequency $(n)$ & Percentage (\%) \\
\hline $11-20$ & 4 & 7.4 & 2 & 4.3 & 6 & 6 \\
\hline $21-30$ & 17 & 31.5 & 15 & 32.6 & 32 & 32 \\
\hline $31-40$ & 11 & 20.4 & 12 & 26.1 & 23 & 23 \\
\hline $41-50$ & 5 & 9.3 & 8 & 17.4 & 13 & 13 \\
\hline $51-60$ & 8 & 14.8 & 6 & 13.0 & 14 & 14 \\
\hline$>60$ & 9 & 16.7 & 3 & 6.5 & 12 & 12 \\
\hline Total & 54 & 100 & 46 & 100 & 100 & 100 \\
\hline Mean \pm SD & \multicolumn{2}{|l|}{$41.05 \pm 17.94$} & \multicolumn{2}{|l|}{$37.58 \pm 13.59$} & \multicolumn{2}{|l|}{$39.46 \pm 16.1$} \\
\hline
\end{tabular}
ness of voice (-Table 2 ).

Table 1 Distribution of the study subjects based on age group and gender $(n=100)$

Abbreviation: SD, standard deviation. 
Table 2 Distribution of the study subjects based on occupation $(n=100)$

\begin{tabular}{|c|c|c|c|}
\hline \multicolumn{2}{|l|}{ Occupation } & Frequency $(n)$ & Percentage (\%) \\
\hline \multicolumn{2}{|l|}{ Businessman } & 12 & 12 \\
\hline \multicolumn{2}{|l|}{ Farmer } & 13 & 13 \\
\hline \multicolumn{2}{|l|}{ Housewife } & 15 & 15 \\
\hline \multicolumn{2}{|l|}{ Laborer } & 29 & 29 \\
\hline \multirow[t]{5}{*}{ Occupations requiring excessive voice use $(n=31)$} & Receptionist & 3 & 3 \\
\hline & Salesperson & 11 & 11 \\
\hline & Singer & 3 & 3 \\
\hline & Student & 7 & 7 \\
\hline & Teacher & 7 & 7 \\
\hline \multicolumn{2}{|l|}{ Total } & 100 & 100 \\
\hline
\end{tabular}

Maximum number of patients (49\%) had duration of hoarseness of voice for 1 to 3 months, $22 \%$ had symptoms for less than 1 month, $13 \%$ for 3 to 6 months, and $8 \%$ had hoarseness for 6 months to 1 year and more than 1 year each.

Associated complaints along with hoarseness of voice were cough and cold (38\%), painful swallowing (19\%), fever (15\%), weight loss (11\%), difficulty in swallowing (10\%), vocal fatigue (14\%), neck swelling (6\%), and respiratory distress (9\%).

Most common etiology for hoarseness of voice encountered was chronic laryngitis in $20 \%$ cases, chronic hyperplastic laryngitis in $6 \%$, and chronic hyperemic laryngitis in $14 \%$, followed by carcinoma larynx seen in 14\% and acute laryngitis in $12 \%$ cases. Whereas vocal cord palsy was seen in $13 \%$, reflux laryngitis and Reinke's edema was seen in 7\% patients each. Vocal cord nodule (9\%), vocal cord polyp (8\%), and vocal cord cyst (4\%) were the benign lesions causing hoarseness of voice. Functional and tubercular etiology was found in $3 \%$ cases each ( $\mathbf{- T a b l e ~} \mathbf{3}$ ).

Multiple predisposing factors were found in patients of hoarseness of voice. Smoking was the most common predisposing factor affecting 35\% among all the cases followed by vocal abuse (25\%) and tobacco chewing (20\%).

As shown in - Table 4, smoking was the major predisposing factor in cases of carcinoma larynx (10 out of 14), chronic laryngitis (9 out of 20), and Reinke's edema (5 out of 7), whereas vocal abuse was the main predisposing factor in cases of vocal cord nodule ( 8 out of 9 ), vocal cord polyp (6 out of 8 ), and vocal cord cyst ( 3 out of 4 ). Upper respiratory tract infections (10 out of 12 ) were the major predisposing factor in cases of acute laryngitis, while gastroesophageal reflux ( 7 out of 7 ) was the most common predisposing factor in reflux laryngitis.

\section{Discussion}

It should be re-emphasized that hoarseness is not a disease in itself, rather a symptom of disease or disturbance in the larynx or along the course of laryngeal motor nerve. It is often first or the only sign of serious local or systemic disease.

A total of 100 cases were examined during the study period. In our study $(n=100), 54 \%$ patients were males and $46 \%$ were females with male to female ratio of $1.17: 1$. This coincides with the studies done by Vengala et $\mathrm{al}^{4}$ and Rao et $a{ }^{5}$ with male: female ratio (M:F) of $1.28: 1$ and $2: 1$, respectively. This could be attributed to the fact that males indulge more in smoking, alcoholism, pollutant exposure, and misuse of voice.

In the present study, mean age of patients with hoarseness of voice was $41.05 \pm 17.94$ years and majority of patients were seen in age group of third decade (32\%) followed by fourth decade (23\%). This correlates with the study by Goswami et $\mathrm{al}^{6}$ and Rathi and Sharma. ${ }^{7}$ Gupta and Jamwal et $\mathrm{al}^{8}$ found majority of patients (20\%) in fifth decade. Also, in Kiakojoury et al study, highest prevalence of voice disorders was found in patients of age $<45$ years. ${ }^{9}$

In our study, $53 \%$ patients were from rural area and $47 \%$ from urban area. This finding is consistent with Goswami et $\mathrm{al}^{6}$ study and Rathi and Sharma study ${ }^{7}$ who found 53.3 and $71.42 \%$ patients, respectively, belonging to rural area.

In our study, we had a study population of varied occupation. Laborers (29\%) constituted the single largest group having hoarseness of voice followed by housewives (15\%). The results are consistent with the studies by Vengala et al, ${ }^{4}$ Rao et al, ${ }^{5}$ and Pal et al. ${ }^{10}$ While in study by Gupta and Jamwal, 31\% of housewives and $30 \%$ of businessman were most affected group. ${ }^{8}$ In a retrospective study of Banjara et al, housewives (19.52\%) were the largest group of patients affected by hoarseness of voice followed by laborer (17.53\%), farmers (17.53\%), and private job/businessman (15.94\%), respectively. ${ }^{11}$

In the present study, duration of hoarseness ranged from 2 days to 3 years. Most of the patients (71\%) had hoarseness of voice for less than 3 months. In Banjara et al study, most of the presenting symptoms (61.35\%) were seen within 3months. ${ }^{11}$ Nanwani et al noticed maximum cases $(45.3 \%)$ presented with 1 to 12 weeks of onset of hoarseness followed by $28 \%$ between 3 and 6 months. ${ }^{12}$

In our study, smoking (35\%) was the commonest predisposing factor followed by vocal abuse (25\%). This finding was consistent with Vengala et al, who also found smoking $(29.45 \%)$ and vocal abuse $(25.34 \%)$ as common predisposing factors. ${ }^{4}$ In the studies by Pal et $\mathrm{al}^{10}$ and Soni and Chouksey, ${ }^{13}$ history of smoking was found in 33 and 60\% cases, respectively, and was a major predisposing factor. 
Table 3 Distribution of the study subjects based on etiology of hoarseness of voice $(n=100)$

\begin{tabular}{|l|l|l|l|}
\hline \multicolumn{2}{|l|}{ Etiology } & Frequency (n) & Percentage (\%) \\
\hline \multirow{2}{*}{ Carcinoma $(n=14)$} & Carcinoma glottis & 4 & 4 \\
\cline { 2 - 4 } & Carcinoma supraglottis & 8 & 8 \\
\cline { 2 - 4 } & Carcinoma subglottis & 2 & 2 \\
\hline Acute laryngitis & Chronic hyperplastic laryngitis & 12 & 12 \\
\hline Chronic laryngitis $(n=20)$ & Chronic hyperemic laryngitis & 6 & 6 \\
\hline Tubercular laryngitis & & 14 & 14 \\
\hline Reinke's edema & & 3 & 3 \\
\hline Vocal polyp & 7 & 7 \\
\hline Vocal cord nodules & 8 & 8 \\
\hline Vocal cord cyst & Idiopathic & 9 & 9 \\
\hline Vocal cord palsy $(n=13)$ & latrogenic & 4 & 4 \\
\hline Functional voice disorder & & 11 \\
\hline Reflux laryngitis & 2 & 2 \\
\hline
\end{tabular}

Table 4 Distribution of study subjects with respect to etiology and predisposing factors $(n=100)$

\begin{tabular}{|c|c|c|c|c|c|c|c|c|}
\hline \multirow[t]{2}{*}{ Etiology } & \multicolumn{8}{|c|}{ Frequency of predisposing factors } \\
\hline & Alcohol & Smoking & $\begin{array}{l}\text { Tobacco } \\
\text { chewing }\end{array}$ & $\begin{array}{l}\text { Vocal } \\
\text { abuse }\end{array}$ & GERD & URTI & Trauma & No risk factor \\
\hline $\begin{array}{l}\text { Acute laryngitis } \\
(n=12)\end{array}$ & 4 & 5 & 2 & 0 & 2 & 10 & 0 & 0 \\
\hline $\begin{array}{l}\text { Carcinoma } \\
\text { larynx }(n=14)\end{array}$ & 4 & 10 & 12 & 0 & 2 & 2 & 0 & 1 \\
\hline $\begin{array}{l}\text { Chronic laryngi- } \\
\text { tis }(n=20)\end{array}$ & 4 & 9 & 1 & 2 & 2 & 3 & 0 & 4 \\
\hline $\begin{array}{l}\text { Tubercular laryn- } \\
\text { gitis }(n=3)\end{array}$ & 0 & 1 & 0 & 0 & 0 & 0 & 0 & 2 \\
\hline $\begin{array}{l}\text { Reinke's edema } \\
(n=7)\end{array}$ & 2 & 5 & 0 & 5 & 2 & 0 & 0 & 0 \\
\hline $\begin{array}{l}\text { Vocal cord } \\
\text { nodules }(n=9)\end{array}$ & 1 & 0 & 0 & 8 & 0 & 1 & 0 & 1 \\
\hline $\begin{array}{l}\text { Vocal cord polyp } \\
(n=8)\end{array}$ & 0 & 2 & 1 & 6 & 1 & 0 & 0 & 1 \\
\hline $\begin{array}{l}\text { Vocal cord cyst } \\
(n=4)\end{array}$ & 0 & 0 & 1 & 3 & 0 & 0 & 0 & 0 \\
\hline $\begin{array}{l}\text { Vocal cord palsy } \\
(n=13)\end{array}$ & 1 & 2 & 1 & 0 & 0 & 0 & 2 & 7 \\
\hline $\begin{array}{l}\text { Functional voice } \\
\text { disorder }(n=3)\end{array}$ & 0 & 0 & 0 & 1 & 0 & 0 & 0 & 2 \\
\hline $\begin{array}{l}\text { Reflux laryngitis } \\
(n=7)\end{array}$ & 1 & 1 & 2 & 0 & 7 & 1 & 0 & 0 \\
\hline Total & 17 & 35 & 20 & 25 & 16 & 17 & 2 & 18 \\
\hline
\end{tabular}

Abbreviations: GERD, gastroesophageal reflux disease; URTI, upper respiratory tract infection.

In our study, commonest etiology observed was chronic laryngitis (20\%) followed by malignancy of larynx (14\%) and acute laryngitis (12\%). In study by Vengala et al, common etiopathologies were acute laryngitis in $30.82 \%$ cases followed by chronic laryngitis (19.86\%) and malignancy (13.01\%). ${ }^{4}$ Rathi and Sharma found vocal cord paralysis as a leading cause of hoarseness seen (23.01\%) followed by malignancy (16.66\%) and vocal nodule (15.07\%). ${ }^{7}$ In Kiakojoury et al study, out of total 197 patients, vocal nodule (24.4\%) and Reinke's edema $(23.4 \%)$ were the commonest causes for hoarseness of voice. ${ }^{9}$ Laryngeal carcinoma (2.5\%) and trauma (2.3\%) were least common cause of all. Category wise organic dysphonia 
(85.78\%) was found to be the most common cause of voice disorders, while functional and neurological dysphonia was seen in 8.6 and $5.6 \%$ of patients, respectively. ${ }^{9}$ In the present study, functional dysphonia was seen in $3 \%$ cases and vocal cord palsy in $13 \%$ cases.

\section{Conclusion}

Hoarseness of voice is an alarming symptom and should not be ignored. Impact of laryngeal disorders on patient's quality of life is significant specially in those who have to use their voice as their profession. In our study, younger population of third decade affected more with male predominance. Smoking was the commonest predisposing factor and chronic laryngitis was the most common etiology for hoarseness of voice. It is easier to get rid of abusive habits that are not of lengthy period. Abstinence of tobacco preparations and alcohol and avoidance of vocal abuse can lead to significant reduction in the incidence of hoarseness of voice and most of the etiological factors can be treated successfully.

\section{Conflict of Interest}

None declared.

\section{References}

1 Marker ON. The reliability of coding paralanguage: pitch, loudness, and tempo.JVerbal Learn Verbal Behav 1965;4(4):306-308

2 Parikh NP. Aetiological study of 100 cases of hoarseness of voice. Indian J Otolaryngol 1991;43(2):71-73
3 Rosen CA, Anderson D, Murry T. Evaluating hoarseness: keeping your patient's voice healthy. Am Fam Physician 1998;57(11):2775-2782

4 Vengala R, Kapilavaya N, Suraneni V. Evaluation of clinical profile and etiopathology for hoarseness of voice- a study of 146 cases. Int J Med Research Rev 2015;3(2):167-173

5 Rao SV, Sharma VS, Subba Rao MV, et al. Etiopathology of hoarseness of voice: a clinical study. Int J Phonosurg Laryngol 2016;6(2):64-67

6 Goswami S, Kesarwaani S, Basumata DK. Clinicopathological study of hoarseness of voice. Sch J Appl Med Sci 2018;6(4):1863-1870

7 Rathi A, Sharma S. Clinicopathological profile of hoarseness of voice. Int J Otorhinolaryngol Head Neck Surg 2020;6(3):484-488

8 Gupta A, Jamwal PS. Clinical study of 100 cases of hoarseness of voice: a hospital-based study. Int J Otorhinolaryngol Head Neck Surg 2018;4(6):1355-1358

9 Kiakojoury K, Dehghan M, Hajizade F, Khafri S. Etiologies of dysphonia reffered to ENT clinics based on videolaryngoscopy. Iran J Otorhinolaryngol 2014;26(76):169-174

10 Pal KS, Kaushal AK, Nagpure PS, Agarwal G. Etiopathological study of 100 patients of hoarseness of voice: in a rural based hospital. Indian J Otolaryngol Head Neck Surg 2014;66(1):40-45

11 Banjara H, Mungutwar V, Singh D, Gupta A. Hoarseness of voice: a retrospective study of 251 cases. Int J Phonosurg Laryngol 2011;1(1):21-27

12 Nanwani P, Nigam R, Jain AK. Clinico-aetiological study of hoarseness of voice. J Med Sci Clin Res 2019;7(1):686-691

13 Soni S, Chouksey S. A study of clinicopathological profile of patients of hoarseness of voice presenting to tertiary care hospital. Indian J Otolaryngol Head Neck Surg 2017;69(2):244-247 